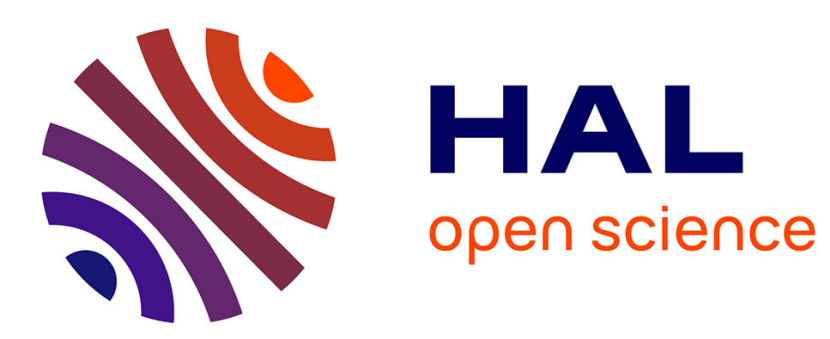

\title{
New material with strong electro-optic effect: Rubidium hydrogen selenate (RbHSeO4)
}

\author{
Jean-Paul Salvestrini, Marc D. Fontana, Michel Aillerie, Z. Czapla
}

\section{To cite this version:}

Jean-Paul Salvestrini, Marc D. Fontana, Michel Aillerie, Z. Czapla. New material with strong electrooptic effect: Rubidium hydrogen selenate (RbHSeO4). Applied Physics Letters, 1994, 64 (15), pp.19201922. 10.1063/1.111742 . hal-00186053

\section{HAL Id: hal-00186053 \\ https://hal.science/hal-00186053}

Submitted on 2 Dec 2021

HAL is a multi-disciplinary open access archive for the deposit and dissemination of scientific research documents, whether they are published or not. The documents may come from teaching and research institutions in France or abroad, or from public or private research centers.
L'archive ouverte pluridisciplinaire HAL, est destinée au dépôt et à la diffusion de documents scientifiques de niveau recherche, publiés ou non, émanant des établissements d'enseignement et de recherche français ou étrangers, des laboratoires publics ou privés. 


\title{
New material with strong electro-optic effect: Rubidium hydrogen selenate $\left(\mathrm{RbHSeO}_{4}\right)$
}

\author{
J. P. Salvestrini, M. D. Fontana, and M. Aillerie \\ Laboratoire Matériaux Optiques à Propriètès Spècifiques-C.L.O.E.S., University of Metz and Supelec, \\ 2 rue Ed. Belin, 57078 Metz Cedex 3, France \\ Z. Czapla \\ Institute of Experimental Physics, University of Wroclaw, 50-204 Wroclaw; Pl. Maxa Borna 9, Poland
}

(Received 17 June 1993; accepted for publication 6 December 1993)

A very large electro-optic Pockels coefficient is reported in a crystal of rubidium hydrogen selenate. This new material is found to be promising for modulation applications because of its very low half-wave voltage $(\sim 27 \mathrm{~V})$ which is determined.

The use of highly efficient devices for the treatment of the optical signal continuously drives the research of new optical materials for various specific applications. Thus, demands for wideband electro-optic modulators using the Pockels effect need high optical quality materials with large electro-optical coefficients and other requirements such as low dielectric losses and permittivity.

Especially interesting for electro-optic and nonlinear optic applications, ${ }^{\mathrm{I}}$ the group of the hydrogen-bonded compounds has been largely studied and well known for a long time; especially, the $\mathrm{KDP}\left(\mathrm{KH}_{2} \mathrm{PO}_{4}\right)$ and $\mathrm{ADP}\left(\mathrm{NH}_{4} \mathrm{H}_{2} \mathrm{PO}_{4}\right)$ crystals are widely used in different commercially available systems. This letter concerns the first investigation of the electro-optical properties in a single crystal of rubidium hydrogen selenate which is less studied and belongs to the same family as KDP and ADP.

Very large electro-optic coefficients are obtained for the first time in this new material which seems to be promising and may be very interesting for opto-electronic devices, particularly for modulation applications. In addition, the low dielectric permittivity and the weak thermo-optic coefficient, are other advantages of this material in regard to requirements for modulators.

Rubidium hydrogen selenate $\mathrm{RbHSeO}_{4}$ is a crystal which presents the triclinic symmetry at room temperature, with pseudo-orthorhombic lattice parameters. ${ }^{2}$ It possesses ferroelastic, pyroelectric, and ferroelectric properties, which have been widely studied. ${ }^{3,4}$ Most investigations in this crystal concern the study of phase transitions in relation with these properties.

The investigation of the electro-optic properties in triclinic crystals is not simple since, owing to the symmetry, all the components of the electro-optic tensor are allowed.

In the configuration used in our experiments, where $\mathbf{E}$ is applied along the $y$ axis and the light propagation is along the $z$ axis the index ellipsoid of the crystal in the presence of an applied electric field is given by

$$
\left(1 / n_{1}^{2}+r_{12} E\right) x^{2}+\left(1 / n_{2}^{2}+r_{22} E\right) y^{2}+2 r_{62} E x y=1,
$$

where $n_{1}, n_{2}$ are the refractive indices in the principal axis system of the crystal without applied field and $r_{12}, r_{22}$, and $r_{62}$ the electro-optic coefficients. According to the crossed term which appears in Eq. (1), the indicatrix of the crystal under the electric field undergoes a rotation with an angle $\theta$ around the $z$ axis given by

$$
\operatorname{tg} 2 \theta=\left(2 r_{62} E\right) /\left[\left(1 / n_{1}^{2}-1 / n_{2}^{2}\right)+\left(r_{12}-r_{22}\right) E\right] .
$$

In such a case one generally finds a new axis system where the indicatrix is diagonalized. ${ }^{5,6}$ Two situations can be encountered according to the magnitude of the angle $\theta$. In the general case, the change of the birefringence due to the applied electric field is expressed as a complicated combination of the various electro-optic effects involving different powers of the electric field $E$ and the coefficients $r_{12}, r_{22}$, and $r_{62}$. In our case, the angle $\theta$ is very small $\left[\left(1 / n_{1}^{2}-1 / n_{2}^{2}\right) \gg r_{62} E\right]$, then the variation of the birefringence depends only on the effective coefficient $r_{b}=r_{22}-\left(n_{1}^{3} / n_{2}^{3}\right) r_{12}$, and is simply linear with the electric field $E$. So the electric field-induced phase shift between $x$ and $y$ light polarization components is expected to depend on the dc voltage amplitude $V=E x d$ as

$$
\Gamma_{E}=(\pi L) /(\lambda d)\left(n_{2}^{3} r_{22}-n_{1}^{3} r_{12}\right) V=(\pi L / \lambda d) n_{2}^{3} r_{b} V
$$

or

$$
\Gamma_{e}=(\pi L / \lambda d) F V,
$$

where $d$ is the interelectrode spacing, $L$ is the crystal length along the laser beam propagation direction, $\lambda$ is the wavelength of the laser beam, and $F$ is the figure of merit of malerials used for modulation applications.

A good optical quality crystal used in our measurements was obtained by isothermal evaporation from aqueous solution and is of the shape of a parallelepiped with the dimensions $7.49 \times 3.02 \times 1.88 \mathrm{~mm}^{3}$ with respect to the pseudoorthorhombic axes. The faces have been polished and electroded with silver paste.

Electro-optic measurements were performed with an original and very sensitive method ${ }^{7}$ which is based upon the Sénarmont compensating setup. The optical transmission of such an optical system follows the general law: $\mathbf{I}=\mathbf{I}_{0} \times \sin ^{2}(\Gamma / 2-\beta+\pi / 4)$ if the optical absorption is neglected. In this equation $I_{0}$ and $I$ are, respectively, the input and output laser intensity and $\Gamma$ the total phase shift introduced by the sample due to the natural birefringence and/or its variation as a function of the temperature, the electric field or the strain applied to the sample. Here, we are only 


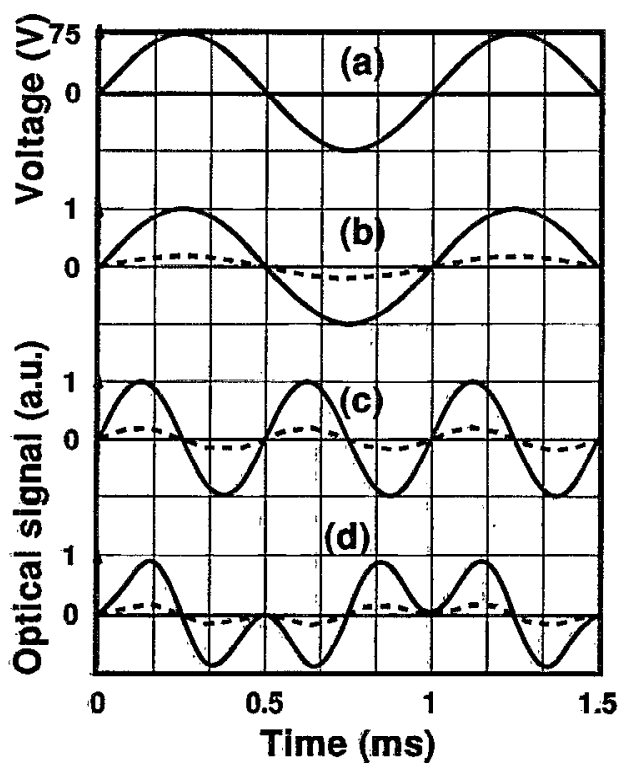

FIG. 1. Performances of the electro-optic modulation obtained with a rubidium hydrogen selenate crystal: (a) applied ac voltage with $f=1 \mathrm{kHz}$; (b) modulated optical signal obtained at $1 \mathrm{kHz}$ for $\mathrm{RbHSeO}_{4}$ (solid line) and ADP (dashed line); (c) optical signal obtained at the double frequency, corresponding to a minimum transmission; (d) optical signal obtained when a de voltage is applied to the crystal. It corresponds to a shift in comparison with double frequency position induced by a de value of $1 \mathrm{~V}$ for $\mathrm{RbHSeO}_{4}$ and $100 \mathrm{~V}$ for $\mathrm{ADP}$ or a phase shift $\Gamma$ of $14^{\circ}$.

concerned about the dependence on the electric field. In this method an ac voltage with a frequency $f$ is superimposed on a dc voltage and we measure the angle $\beta_{2 f}$ of the analyzer corresponding to the detection of the output signal with the frequency $2 f$.

Measurements are carried out with an electric field applied along the $y$ axis and a laser beam of $633-\mathrm{nm}$ wavelength propagating along the $z$ axis. They are performed around room temperature with an ac modulating voltage of $150 \mathrm{~V}$ peak-to-peak and frequency varying between $100 \mathrm{~Hz}$ to $1 \mathrm{MHz}$, and a dc voltage amplitude between -150 and $300 \mathrm{~V}$.

Without applying electric field the crystal presents a spontaneous birefringence and thus a natural phase shift which needs to be compensated by an appropriate rotation of the analyzer. A clear modulation of the laser beam is achieved with the $\mathrm{RbHSeO}_{4}$ crystal for all available frequencies of the modulation field, from $100 \mathrm{~Hz}$ up to $1 \mathrm{MHz}$. An example of the modulated signal which is recorded for a modulation frequency $f=1 \mathrm{kHz}$ is given in Fig. 1, and compared with the corresponding signal obtained with an ADP crystal. The high sensitivity of our method and the large efficiency of the rubidium hydrogen selenate crystal are clearly pointed out in this figure.

The phase shift $\Gamma_{E}=2 \times \beta_{2 f}$ obtained at $T=23.8{ }^{\circ} \mathrm{C}$ for a modulation frequency $f=1 \mathrm{kHz}$ is plotted as a function of the dc voltage in Fig. 2. It exhibits a remarkably linear behavior with the applied voltage up to $90 \mathrm{~V}$ but deviates from this law for amplitude larger than $100 \mathrm{~V}$ and finally saturates. The result is checked to be completely reproducible for various samples. On the other hand, if we compare the values

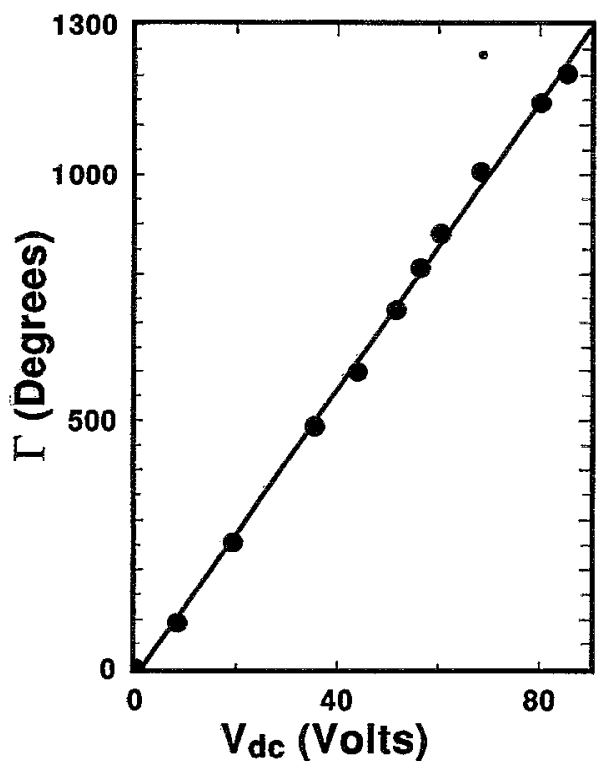

FIG. 2. Electric field-induced phase shift $\Gamma_{E}$ obtained at $23.8^{\circ} \mathrm{C}$ for an ac applied field of $150 \mathrm{~V}$ peak-to-peak with a modulation frequency $f=1 \mathrm{kHz}$.

which are obtained for a zero voltage reached with increasing or decreasing amplitude the shift is very large and is equal to $428^{\circ}$. This large memory effect ${ }^{8}$ is also obtained after switching off the electric field applied to the crystal. Both these phenomena are probably attributable to the domain reversal and require special investigation of the change of birefringence in relation with the domain structure.

Here, we focus our attention on the linear dependence of the phase shift which is consistent with Fig. 2, revealing the electro-optic coefficient $r_{b}$. We can, therefore, deduce from the experimental data and Eq. (3) the figure of merit $F=n_{2}^{3} r_{b}$ of the crystal. We obtain $F=13.5 \times 10^{-9} \mathrm{mV}^{-1}$. The corresponding half-wave voltage inducing a phase shift $\Gamma_{E}=\pi$ is also derived from Eq. (3) and found to be equal to $V_{\pi}=7 \mathrm{~V}$ for the particular sample used in our experiments. The reduced half-wave voltage characterizing the rubidium hydrogen selenate is obtained when $L / d=1: V_{\pi}^{*}=26.5 \mathrm{~V}$. The values of $F$ and $V_{\pi}^{*}$ obtained for $\mathrm{RbHSeO}_{4}$ are given in Table I and compared with corresponding values reported for the most known electro-optic materials. ${ }^{9}$ This comparison shows that rubidium hydrogen selenate is a very promising material for modulation applications owing to its very large $F$ and its very low half-wave voltage. Deviations from the linear dependence of $\Gamma$ vs $V$ which occur for larger voltage can be indeed easily avoided in applications. In addition, to a rela-

TABLE I. Values of the figure of merit $F=n^{3} \times r_{b}$ and the reduced halfwave voltage $V_{\pi}^{*}$ in various materials at room temperature and for $\lambda=633$ nm.

\begin{tabular}{lcc}
\hline \hline Compounds & $F=n^{3} \times r(\mathrm{pm} / \mathrm{V})$ & $V_{\pi}^{*}(V)$ \\
\hline $\mathrm{BaTiO}_{3}\left(r_{42}\right)$ & 24859 & 332 \\
$\mathrm{KDP}_{(}\left(r_{63}\right)$ & 40 & 15540 \\
$\mathrm{LiNbO}_{3}\left(r_{c}\right)$ & 211 & 2800 \\
$\mathrm{KTP}_{(}\left(r_{c}\right)$ & 184 & 3417 \\
$\mathrm{RbISeO}_{4}$ & 13540 & 26.5 \\
\hline
\end{tabular}


tively low dielectric permittivity, ${ }^{3,4} \mathrm{RbHSeO}_{4}$ possesses also the advantage of a thermo-optic coefficient which is very weak compared to other materials. ${ }^{10}$

${ }^{1} \mathrm{P}$. Gunter, in Electro-Optic and Photorefraciive Materials, edited by $\mathrm{P}$. Gunter (Springer Berlin, 1986), Vol. 18, p. 2.

${ }^{2}$ A. Waskowska, S. Olejnik, K. Lukaszewiz, and T. Glowiak, Acta Crystallogr. Sec. B 34, 3344 (1978).

${ }^{3}$ R. Poprawski, J. Mroz, Z. Czapla and L. Sobczyk, Acta Phys. Pol. A 55, 641 (1979).
${ }^{4}$ R. Poprawski and S. Matyjasik, Ferroelectrics 81, 57 (1988).

${ }^{5}$ A. Yariv and P. Yeh, Optical Waves in Crystals (Wiley, New York, 1984). ${ }^{6}$ F. Abdi, M. D. Fontana, M. Aillerie, and G. Godefroy, Ferroelectrics 133, 175 (1992).

${ }^{7}$ M. Aillerie, M. D. Fontana, F. Abdi, C. Carabatos-Nedelec, and N. Theophanous, SPIE J. 94, 1018 (1988).

${ }^{8}$ H. Adachi, T. Kawaguchi, K. Setsune, K. Ohji, and K. Wasa, Appl. Phys. Lett. 42, 10 (1983).

${ }^{9}$ J. D. Bierlein and C. B. Arweiler, Appl. Phys. Lett. 49, 15 (1986).

${ }^{10}$ M. Aillerie, M. D. Fontana, F. Abdi, C. Carabatos-Nedelec, N. Theophanous, and G. Alexakis, J. Appl. Phys. 65, 2406 (1989). 